\title{
Cytokine expression in bronchial biopsies of cystic fibrosis patients with and without acute exacerbation
}

\author{
C. Wojnarowski*, T. Frischer*, E. Hofbauer**, C. Grabner*, W. Mosgoeller ${ }^{+}$, I. Eichler*, \\ R. Ziesche**
}

Cytokine expression in bronchial biopsies of cystic fibrosis patients with and without acute exacerbation. C. Wojnarowski, T. Frischer, E. Hofbauer, C. Grabner, W. Mosgoeller, I. Eichler, R. Ziesche. (C)ERS Journal Ltd 1999.

ABSTRACT: In patients with cystic fibrosis (CF), the progression of pulmonary disease differs considerably, even in identical cystic fibrosis transmembrane conductance regulator-genotypes which could reflect an additional influence of the host's immune response. This study therefore measured cytokine expression patterns in $\mathrm{CF}$ patients with different clinical presentation.

Expression of interleukin (IL)-8, interferon gamma (IFN- $\gamma$ ), IL-4, IL-10, and transforming growth factor (TGF) $\beta_{1}$ was assessed in bronchial mucosal biopsies of eight CF patients with acute exacerbation (age 6.0-14.2 yrs), eight CF patients with chronic stable disease (age 7.3-17.4 yrs), and in five normal control subjects by semiquantitative and quantitative reverse transcriptase polymerase chain reaction combined with histopathological assessment and immunohistochemical staining.

All CF patients expressed IL-8. In acute exacerbation, expression of TGF- $\beta_{1}$ and IFN- $\gamma$ was either absent or extremely low. In contrast, all patients with stable disease strongly expressed TGF- $\beta_{1}$. The highest expression of TGF- $\beta_{1}$ and IFN- $\gamma$ was found in CF patients with mild disease and a history of infrequent exacerbations. No correlation was found between the expression of IL-4 and IL-10 and patient history. In normal control subjects, only a weak expression of TGF- $\beta_{1}$ was observed.

These results show a remarkable correlation between cytokine pattern and the clinical course of cystic fibrosis. High expression of transforming growth factor- $\beta_{1}$ and interferon gamma was associated with mild disease, whereas no or very weak expression of these cytokines was typical for patients with acute disease and frequent exacerbations suggesting a contribution of the immune response to the progression of pulmonary disease in cystic fibrosis.

Eur Respir J 1999; 14: 1136-1144.
*Dept of Paediatrics, **Dept of Pulmonary Medicine ${ }^{+}$Institute of Histology and Embryology; University Hospital Vienna, Waehringer Guertel 18-20, A-1090 Vienna, Austria.

Correspondence: C. Wojnarowski University Hospital Vienna

Dept of Paediatrics Waehringer Guertel $18-20$

1090 Vienna

Austria

Fax: 431404003194

Keywords: Bronchial biopsies cystic fibrosis

cytokines

interferon- $\gamma$

interleukin-8

transforming growth factor- $\beta_{1}$

Received: February 161999

Accepted after revision June 221999

This study was supported by the FWF Grant P 11605 Med
Cystic fibrosis (CF) is caused by mutations in the cystic fibrosis-transmembrane conductance regulator (CFTR) gene [1]. Despite this multiorgan involvement, progression of pulmonary involvement decides the clinical outcome in the majority of patients [2]. Progress of pulmonary disease differs considerably, being dependent on the number of endobronchial infections with concomitant destruction of the bronchial tree. Yet it is still a matter of debate whether the different clinical outcome is mainly the result of the underlying genetical defect or the host's immune response itself. This response is characterized by a neutrophil-dominated inflammation [3-5]. During the inflammation, mediators such as interleukin (IL)-1, IL-6, IL-8, IL10 and tumour necrosis factor (TNF)- $\alpha$ ) [6-11] are commonly induced, as seen in sputum, serum and bronchoalveolar lavage (BAL) samples of CF patients. This inflammatory activity is not restricted to acute exacerbations of CF, but has also been demonstrated in mild disease and during chronic stable phases [12-14]. Moreover, in very young infants, substantial inflammatory activity was seen without detection of bacterial and viral pathogens [15] suggesting a chronic upregulation of the immune response despite a lack of detectable pathogens. In addition, anti- biotic treatment alone was unable to suppress airway inflammation [16].

Based on these facts, it was hypothesized that the clinical presentation of CF patients might be reflected by a different pattern of immune reaction in patients with acute exacerbation versus patients with chronic stable disease. Thus, this study measured the transcription of proinflammatory mediators resembling an acute immune response, such as IL-8, and interferon gamma (IFN- $\gamma$ ), and of a more chronic inflammatory pattern, such as IL-4, IL-10, and transforming growth factor (TGF)- $\beta_{1}$ in bronchial mucosal biopsies of $\mathrm{CF}$ patients with acute exacerbation or chronic stable disease by qualitative and quantitative reverse transcriptase polymerase chain reaction (RT-PCR). For negative controls, patients without bronchial inflammation were investigated.

\section{Patients}

Materials and methods

CF patients were recruited from the authors' outpatient clinic. In all patients, the diagnosis of CF was based on 
iontophoretic sweat chloride levels of $>60 \mathrm{mEq} \cdot \mathrm{L}^{-1}$ in a pilocarpine-induced sweat sample of $>100 \mathrm{mg}$, and patients were screened for the 12 most common mutations of CFTR genotypes occuring in the study population (dF508, 1717-1G >A, G542X, W1282X, N1303K, 3849+10kbC >T, 621+1G>T, R553X, G551D, R117H, R1162X, R334W). For this study, only CF patients with an acute pulmonary exacerbation were enrolled, who had a medical indication for bronchoscopy (such as inconclusive bacteriology from sputum cultures or persistent atelectasis) as given by a CF specialist not participating in this study. Acute pulmonary exacerbation was defined by increased cough and sputum production, fever with or without new pulmonary infiltrates, weight loss, deterioration of oxygen saturation and $>10 \%$ decline of predicted forced expiratory volume in one second (FEV1). For clinically stable disease, CF patients without acute exacerbation and no need of intravenous or peroral antibiotic or corticosteroid treatment in the last 3 months were chosen. At the time of enrolment, all patients in this group had an indication for general anaesthesia (seven patients for nasal sinus surgery, one mentally retarded patient for dental surgery). Bronchoscopy was performed prior to the operation. For negative controls, one patient having a pulmonary sling operation, one patient with thoracic surgery for removal of a pulmonary metastase, and three patients with resection of a pulmonary sequester were studied. At the time of bronchoscopy, signs of general and bronchial inflammation were absent in all patients. Additionally, in the latter four patients, samples were taken from the contralateral side.

All patients had a physical examination, chest radiography, and routine blood samples. In CF patients, the number of peroral and intravenous antibiotic cycles with a duration $\geq 14$ days in the preceding 12 months was recorded. Lung function (LF) tests were performed according to the American Thoracic Society (ATS) standards [17]. Vital capacity and FEV1 were recorded by a maximum flow volume curve (Masterlab; E. Jaeger, Würzburg Germany). Results were expressed as percent predicted based on accepted reference standards [18].

Written informed consent was gathered prior to the enrolment by the patients and the patient's caregivers. The study protocol was approved by the Institutional Review Board of the University Hospital Vienna.

\section{Bronchoscopies}

The bronchoscopy procedure was the same in all patients. In case of surgical intervention, bronchoscopy was performed prior to the operation. Patients were fasted for a minimum of $6 \mathrm{~h}$. Bronchoscopies were performed with Olympus BFP30 bronchoscope (Olympus, Tokyo, Japan) according to the authors standard procedures under light general anaesthesia (midazolam $0.1 \mathrm{mg} \cdot \mathrm{kg}^{-1}$ and propofol 3-7 $\mathrm{mg} \cdot \mathrm{kg}^{-1}$ intravenously, and $0.2 \mathrm{mg} \cdot \mathrm{kg}^{-1}$ nalbuphinehydrochloride, intravenously). Patients were closely monitored by direct observation from a paediatric anaesthesiologist, for continuous pulse rate, oxygen saturation measurements and intermittent blood pressure recording throughout the procedure. After premedication with glycopyrrolate $\left(0.01 \mathrm{mg} \cdot \mathrm{kg}^{-1}\right)$ the bronchoscope was introduced through a laryngeal mask with the patient in a supine position. Lidocaine solution ( $2 \%$ ) was administered through the bronchoscope channel to provide topical anaesthesia of the larynx and the trachea. The total airway dose of lidocaine did not exceed $3 \mathrm{mg} \cdot \mathrm{kg}^{-1}$. Bronchial fluid was submitted for bacterial and fungal cultures. Five mucosal biopsies were taken from the subcarinae of the right lower and middle lobe with Olympus BF19C forceps. After bronchoscopy, all subjects were closely observed for $4 \mathrm{~h}$, and chest radiographs were repeated. For RT-PCR, samples were immediately snap frozen in liquid nitrogen, for immunohistochemistry, specimens were fixed immediately in $4 \%$ freshly depolimerized paraformaldehyde for $2 \mathrm{~h}$ at $4{ }^{\circ} \mathrm{C}$, washed in phosphate buffered saline (PBS) three times 20 min each at room temperature, dehydrated and paraffin embedded according to standard procedures.

\section{Histological assessment}

Sections $2 \mu \mathrm{m}$ thick were used for routine haematoxilineosin staining. Sections were randomly numbered in order to blind the investigator about the clinical history. The cellular pattern of infiltration within the epithelium and the subepithelial mucosa was assessed. In addition, immunohistochemistry was performed with monoclonal antibodies for IL-8, TGF- $\beta_{1}$ and IFN- $\gamma$. For immunohistochemical staining, 3-4 $\mu \mathrm{m}$ sections were mounted on silanized slides, dewaxed ( $3 \times$ xylol for $15 \mathrm{~min})$, and gradually rehydrated in the decreasing alcohol series. Sections were then washed in PBS $(2 \times)$, and pre-incubated in blocking solution (PBS, $10 \%$ FCS, $0.05 \%$ Tween-20). The primary and secondary antibodies were diluted in the same blocking solution. Rabbit anti-human IFN- $\gamma$ (Serotec, Oxford, UK, final dilution 1:200) was incubated at room temperature for 30 min. Monoclonal anti-TGF- $\beta_{1}$ (Santa Cruz, CA, USA, final dilution $1: 150$ ) was incubated $16-20 \mathrm{~h}$ at room temperature. Monoclonal anti-lL-8 immunoglobulin (Ig)G1 (Boehringer Ingelheim, Heidelburg, Germany, final dilution 1:50) was incubated overnight in a moist chamber at $4{ }^{\circ} \mathrm{C}$. Following incubation with the first antibody, the slides were washed in 3\&times; PBS for $10 \mathrm{~min}$ ), and secondary antibodies (alkaline phosphatase-conjugated goat antimouse immunoglobulins (Dako, Glostrup, Denmark, final dilution 1:40), or alkaline phosphatase-conjugated antirabbit immunoglobulines (Boehringer Mannheim, Manheim, Germany, final dilution 1:200) were added. Additional washes in PBS $(3 \times)$ and a 2 min incubation with an alkaline buffer $(100 \mathrm{mM}$ Tris-HCl, $100 \mathrm{n} \mathrm{mM} \mathrm{NaCl}, 50 \mathrm{mM}$ $\mathrm{MgCl}_{2}, \mathrm{pH}$ 9.5) were performed. For colour development, the NBT:BCIP system (Boehringer Mannheim) was used throughout the experiments, with additional levamisole added to the reaction buffer. The reaction time for IL- 8 was $\sim 4-6 \mathrm{~h}$, for TGF- $\beta_{1} 2 \mathrm{~h}$ and for IFN- $\gamma 20 \mathrm{~min}$. Some slides labelled with TGF- $\beta_{1}$ and IL- 8 were incubated with antibodies specific for lysozyme, and a protein specific for monocytes and neutrophil granulocytes. In this case, the colour substrate was fast red, which developed visible precipitates within $5 \mathrm{~min}$.

For negative controls, secondary antibodies were added after nonspecific staining. To test for nonspecific alkaline phosphatase reaction, several sections were incubated without antibodies, and subsequently treated with nitrobluetetrazolium (NBT): 5-bromo-4-chloro-3indolyl Phosphat (BCIP) substrate solution. No signal was detected in negative controls.

Out of five biopsies from each patient, two were analysed separately and histological and immunohistochemical assessment was performed at various sites within these biopsies. 
To further characterize the role of polymorphonuclear cells (PMNs) or lymphatic cells in the inflammatory process in exacerbating and stable patients, sections stained with haematoxylin-eosin or immunostained for TGF- $\beta_{1}$ and IL-8 were statistically evaluated. To facilitate the attribution of immunoreactive infiltrating cells under experimental low contrast conditions, dual colour double staining techniques with anti-lysozyme antibodies (Dako, Denmark), and an enzyme staining for PMNs and monocytic derivates were used. This procedure allowed for the histological differentiation of PMNs and lymphatic cells by means of lysozyme reactivity and nuclear morphology. Cells in the sections were identified as either PMNs or of lymphatic origin and were counted over a field corresponding to $16,300 \mu \mathrm{m}$. The cell densities were then subjected to statistical analysis by the Wilcoxon rank sum test.

\section{Reverse transcriptase polymerase chain reaction}

Total cytoplasmic ribonucleic acid (RNA) was extracted by the acid guanidinium thiocyanate method from the frozen mucosal biopsy specimens. Complementary deoxyribonucleic acid (cDNA) synthesis was performed using $1 \mu \mathrm{g}$ of total RNA with 20 pmol oligo (dt) 18 primer using 200 $\mathrm{U} \cdot \mu \mathrm{g}^{-1} \mathrm{RNA}$ Moloney-Murine leukemia virus reverse transcriptase in a total volume of $20 \mathrm{~mL}$. Yield of cDNA was determined by an optical density (OD) reading at 260/280 $\mathrm{nm}$ on an ultraviolet (UV) spectrophotometer (Pharmacia Biotech, Cambridge, UK). One microgram of cDNA was used for semiquantitative PCR. Constitutive control was achieved by amplification of the glyceraldehyde-3-phosphate dehydrogenase (GAPDH) gene with GAPDH amplimers (Clontech laboratories, Paolo Alto, CA, USA). The patient's genes were amplified by the following primers, TGF- $\beta_{1}: 5^{\prime}$-GCC CTG GAC ACC AAC TAT TGC, 3'-AGG CTC CAA ATG TAG GGG CAG; IFN- $\gamma: 5^{\prime}-\mathrm{GCA}$ TCG TTT TGG GTT CTC TTG GCT GTT ACT GC, 3'-CTC CTT TTT CGC TTC CCT GTT TTA GCT GCT GG; IL-4: 5'-ATG GGT CTC ACC TCC CAA CTG CT, 3'-CGA ACA CTT TGA ATA TTT CTC TCT CAT; IL-8: 5'-ATG ACT TCC AAG CTG GCC GTG GCT, 3'-T CTC AGC CCT CTT CAA AAA CTT CTC; IL10: 5'-AAG CTG AGA ACC AAG ACC CAG ACA TCA AGG CG, 3'-AGC TAT CCC AGA GCC CCA GAT CCG ATT TTG G. Specificity of PCR products was controlled by Southern hybridization. PCR was performed in a total volume of $50 \mu \mathrm{L}$. Twentyeight cycles from a hot start PCR were performed on a Perkin-Elmer Thermal Cycler Model 480 (Perkin Elmer, Branchbury, NJ,USA). Cycle conditions were as follows: start $\left(94^{\circ} \mathrm{C}\right.$ for; $\left.4 \mathrm{~min}\right)$, denaturation $\left(94^{\circ} \mathrm{C}, 40 \mathrm{~s}\right.$ for all genes except TGF- $\left.\beta_{1}(45 \mathrm{~s})\right)$, annealing $\left(60^{\circ} \mathrm{C}, 40 \mathrm{~s}\right.$ for IFN-g, IL-4 and IL- $10 ; 60^{\circ} \mathrm{C}, 45 \mathrm{~s}$ for TGF- $\beta_{1}$ and IL-8), and extension $\left(72{ }^{\circ} \mathrm{C}\right.$ for, $2 \mathrm{~min}$ ) followed by an additional extension at $72^{\circ} \mathrm{C}$ for $7 \mathrm{~min}$. Twenty-eight amplification cycles were performed for TGF- $\beta_{1}$, IL-4, IL-8, and IFN- $\gamma$, and 35 amplification cycles for IL-10. Aliquots of $30 \mu \mathrm{L}$ were electrophoretically separated on a $2.8 \%$ NuSieve agarosegenetic technology grade (GTG)/agarose gel (FMC Bioproducts, Rockland, ME, USA) and visualized by ethidium bromide staining. Amplification products for semiquantitative PCR were as follows: TGF- $\beta_{1}, 161$ base pairs (bp); IFN- $\gamma 427$ bp; IL-4 465 bp; IL-10 328 bp; IL-8 289 bp. For quantitation, competitive PCR was performed according to the protocol provided with Clontech's PCR Mimic ${ }^{\circledR}$ sequences. Serial dilutions of the competitor gene ranged from $10-10^{-5}$ amol. Two microlitres of the serial dilutions and 1 $\mu \mathrm{g}$ of the patients cDNA were subjected to the competitive PCR reaction in a total volume of $50 \mu \mathrm{L}$. Aliquots of $30 \mu \mathrm{L}$ were electrophoretically separated on a $2.8 \%$ NuSieve GTG/ agarose gel and visualized by ethidium bromide staining. Out of five biopsies from each patient two to three were separately analysed. Each experiment was performed in duplicate.

\section{Results}

\section{Patients}

During a period of 24 months, eight patients with an acute pulmonary exacerbation (as described above) who had a medical indication for bronchoscopy were enrolled, aged 6.0-14.2 yrs (mean 9.6 yrs, four males and four female children). On average, patients had 3.6 antibiotic cycles throughout the last 12 months. All showed positive BAL cultures for either Pseudomonas aeruginosa (PA), Staphylococcus aureus (SA) or Haemophilus influenzae (HI) as shown in table 1 . In most of the patients, a considerable reduction of FEV1 \% pred values was observed. In table 1 , the individual number of intravenous and/or peroral antibiotic cycles (with a minimal duration of 14 days) in the preceding 12 months is shown. Four patients were homozygous for $\mathrm{dF} 508$, two were heterozygous for $\mathrm{dF} 508$, one for G542X and one patient did not have any of the 12 mutations examined.

Eight patients, four male and four female children, with clinically stable disease were enrolled (table 1). They were in general older than the "acute patients" group (age range 7.3-17.4 yrs, mean 12.3 yrs) and had better FEV1 values irrespective of positive bronchoalveolar lavage cultures for PA, SA, and/or HI. On average, patients had 1.6 antibiotic cycles throughout the last 12 months. In one patient, lung function testing could not be performed because of mental retardation but in clinical terms this patient presented with very mild disease. In the chronic stable group, four patients were homozygous for $\mathrm{dF} 508$, two were heterozygous for dF508, and two patients did not have any of the 12 mutations investigated. One female with a first acute exacerbation improved rapidly after intravenous antibiotic therapy, and a second bronchoscopy was performed 4 months later under clinically stable conditions. Five patients without bronchial inflammation served as normal control subject.

Assessment of transforming growth factor- $\beta_{1}$ transcription by reverse transcription polymerase chain reaction

Figure 1a and $\mathrm{b}$ demonstrates two examples of quantitative RT-PCR analysis for the transcription of the TGF$\beta_{1}$ gene in a CF patient with acute exacerbation (patient 1 ), and in a patient with chronic stable disease (patient 12). Transcription of TGF- $\beta_{1}$ in the patient with chronic stable disease was $10^{-1}$ amol, whereas in the patient with acute CF, TGF- $\beta_{1}$ was absent. TGF- $\beta_{1}$ was transcribed in all patients with chronic stable disease with a maximum 
Table 1. - Characteristics of cystic fibrosis patients with acute pulmonary exacerbation (acute) and chronic stable disease (stable, cytokine transcription rates.

\begin{tabular}{|c|c|c|c|c|c|c|c|c|c|c|c|}
\hline \multirow[t]{2}{*}{ Patient } & \multirow[t]{2}{*}{ yrs } & \multirow[t]{2}{*}{ Genotype } & \multirow[t]{2}{*}{$\begin{array}{c}\operatorname{IgE} \\
\mathrm{KU} \cdot \mathrm{L}^{-1}\end{array}$} & \multirow[t]{2}{*}{ Bacteriology } & \multirow[t]{2}{*}{$\begin{array}{c}\text { FEV1\% } \\
\text { pred }\end{array}$} & \multicolumn{5}{|c|}{ Cytokine transcription rate } & \multirow[t]{2}{*}{$\begin{array}{c}\text { Antibiotic } \\
\text { therapy over } 12 \\
\text { months }\end{array}$} \\
\hline & & & & & & IL-8 & TGF- $\beta_{1}$ & $\mathrm{INF}-\gamma$ & IL-4 & IL-10 & \\
\hline 1 (acute) & 7.4 & $\mathrm{dF} 508 / \mathrm{n}$ & 58 & SAHI & 40.8 & ++++ & - & + & + & ++ & $5 \times$ p.o., $2 \times i . v$. \\
\hline 2 (acute) & 10.7 & dF508/dF508 & 70 & PA & 41.5 & + & - & - & + & ++ & $3 \times$ p.o. \\
\hline 3 (acute) & 9.1 & $\mathrm{dF} 508 / \mathrm{dF} 508$ & 30 & PA & 38.7 & ++ & - & - & - & ++ & $4 \times$ p.o., $1 \times$ i.v. \\
\hline 4 (acute) & 10.9 & $\mathrm{G} 542 \mathrm{X} / \mathrm{n}$ & 131 & SA & 55.6 & + & - & - & ++ & + & $4 \times$ p.o. \\
\hline 5 (acute) & 6.0 & $\mathrm{n} / \mathrm{n}$ & 200 & PA & 76.1 & ++ & - & - & + & ++ & $2 \times$ p.o., $1 \times$ i.v. \\
\hline 6 (acute) & 14.2 & dF508/dF508 & 38 & PASA & 38.5 & + & $(+)$ & + & + & - & $2 \times p . o$ \\
\hline 7 (acute) & 8.9 & $\mathrm{dF} 508 / \mathrm{n}$ & 326 & PA & 43.5 & + & - & - & - & - & $5 \times p . o$ \\
\hline 8 (acute) & 9.2 & $\mathrm{dF} 508 / \mathrm{dF} 508$ & 98 & SAHI & 117.4 & ++ & $(+)$ & n.d. & n.d. & n.d. & 0 \\
\hline 9 (stable) & 14.0 & dF508/dF508 & 200 & PASAHI & 74.8 & ++ & ++ & - & - & ++ & $3 \times p . o$ \\
\hline 10 (stable) & 13.7 & $\mathrm{n} / \mathrm{n}$ & 10 & HI & n.d. & + & +++ & ++ & ++ & + & 0 \\
\hline 11 (stable) & 17.4 & $\mathrm{n} / \mathrm{n}$ & 62 & SA & 110.5 & ++ & +++ & ++ & ++ & + & 0 \\
\hline 12 (stable) & 7.3 & $\mathrm{dF} 508 / \mathrm{n}$ & 67 & PAHI & 127.9 & ++ & +++ & ++ & + & - & 0 \\
\hline 13 (stable) & 16.5 & $\mathrm{dF} 508 / \mathrm{n}$ & 17 & PASA & 41.6 & + & $(+)$ & ++ & - & - & $1 \times$ p.o., $2 \times$ i.v. \\
\hline 14 (stable) & 7.9 & dF508/dF508 & 94 & SA & 57.6 & + & ++ & +++ & - & - & $3 \times$ p.o. \\
\hline 15 (stable) & 14.5 & dF508/dF508 & 11 & SA & 100 & + & + & - & + & + & $3 \times$ p.o. \\
\hline 16 (stable) & 9.5 & dF508/dF508 & 98 & - & 29.2 & + & ++ & n.d. & n.d. & n.d. & $1 \times i . v$. \\
\hline
\end{tabular}

t: Bacterial cultures from bronchial lavages; PA: Pseudomonas aeruginosa; SA: Staphylococcus aureus; HI: Haemophilus influenzae; $\S$ : number of peroral (p.o.) and intravenous (i.v.) antibiotic cycles of $\geq 14$ days. Ig: immunoglobulin; FEV1: forced expiratory volume in one second; IL: interleukin; TGF: transforming growth factor; IFN: interferon n.d.: not determined : - : not detected. Cytokine transcription rate, $(+): 10^{-4} \mathrm{amol} ;+: 10^{-3} \mathrm{amol} ;++: 10^{-2} \mathrm{amol} ;+++: 10^{-1} \mathrm{amol} ;++++: 10 \mathrm{amol}$. Patient number 8 is also patient number 16 , this is because two bronchoscopies were performed on this patient (one during an acute exacerbation and the other during chronic stable disease).

of $10^{-1}$ amol. $\mu \mathrm{L}$ RNA (fig. $1 \mathrm{~b}$ ). In the patients with acute exacerbation of the disease, transcription of TGF- $\beta_{1}$ was either absent or barely detectable. In normal control subjects, only very weak or no expression of TGF- $\beta_{1}$ was found (data not shown).

\section{Transcription of interferon gamma}

Analysis of the transcription rate for IFN- $\gamma$ was possible in seven of eight chronic stable patients (fig. 2). Of these patients, five demonstrated transcription of the IFN- $\gamma$ gene (range $10^{-2}-10^{-1}$ amol $\cdot \mu \mathrm{L}^{-1}$ ). Among patients with acute exacerbation, IFN- $\gamma$ was only transcribed in two patients $\left(10^{-3} \mathrm{amol} \cdot \mu \mathrm{L}^{-1}\right)$, and was undetectable in all others. Due to the small amount of total messenger ribonucleic acid (mRNA) obtained in one patient, additional assessment of IFN-g was not possible. Normal control did not express IFN- $\gamma$ (data not shown).

The associations between cytokine expression and clinical data were investigated using the Wilcoxon rank sum test. CF patients with cytokine expression $\geq 10^{-3}$ amol were compared with patients with cytokine expression $<10^{-3}$ amol. High TGF- $\beta_{1}$ expression was associated with significantly better FEV1 values $(p=0.02)$ and fewer exacerbations in CF patients $(\mathrm{p}<0.05)$, whereas for IFN$\gamma$ the associations were of borderline significance for exacerbations $(\mathrm{p}=0.08)$ and nonsignificant for FEV1.

\section{Transcription of interleukins-4, -8 and -10}

In addition, the transcription rates of IL- 4 and IL-10 genes were investigated in seven patients with acute exacerbation and in seven patients with chronic stable disease (table 1). IL-4 was present in five of the seven patients with acute exacerbation, and in four of the seven patients with chronic stable disease. The expression did not correlate with the serum IgE levels of the patients. IL10 transcripts in relatively high concentrations were seen in five of the patients with acute disease, whereas in chronic stable disease, four of the patients showed IL-10 transcription of low intensity. Neither IL-4 nor IL-10 expression had an obvious association with the clinical appearance. In the normal control subjects, no expression of IL-4 and IL-10 was found (data not shown).

Individual transcription rates for IL-8 in CF patients are shown in table 1 . All patients $(n=16)$ expressed IL-8. In acute $\mathrm{CF}$, transcription of IL-8 gene ranged $1-10^{-3}$ amol. $\mu \mathrm{L}^{-1}$ RNA, whereas in chronic stable disease, transcription of IL-8 was between $10^{-2}-10^{-3}$ amol $\mu \mathrm{L}^{-1}$ RNA. In the normal control subjects $(n=3)$, no expression of the IL-8 gene was found (data not shown).

\section{Histology}

Histopathological assessment of the acute cases revealed oedema and intense cellular infiltrates predominantly in the subepithelial compartment. Most of the infiltrating cells were either PMNs or lymphatic cells. Almost all of these cells were found in a narrow zone adjacent to the basal membrane. The depth of this zone was measured to be $\sim 100-200 \mu \mathrm{m}$. Table 2 summarizes the average number of infiltrating cells in the biopsies. Cell density was found to be highest in the group with acute exacerbation. The number of PMNs and lymphatic cells differed significantly between chronic stable and acute patients. In all cases of acute exacerbation, the number of granulocytes (mainly neutrophils) by far exceeded the amount of lymphocytes. This was very much in contrast to the cellular infiltrates seen in the patients with chronic stable disease, where predominantly lymphocytes and plasma cells were observed. The other difference was related to the epithelial layer itself; in acute disease (fig. 3a), the 
a)

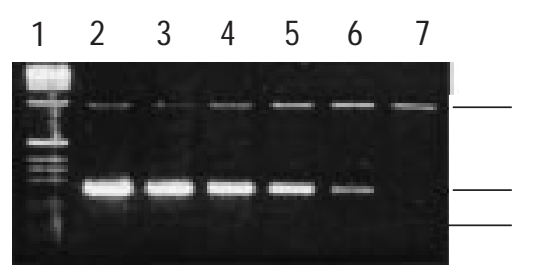

b)

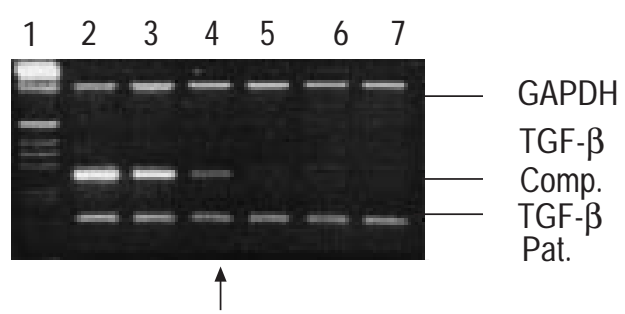

d)

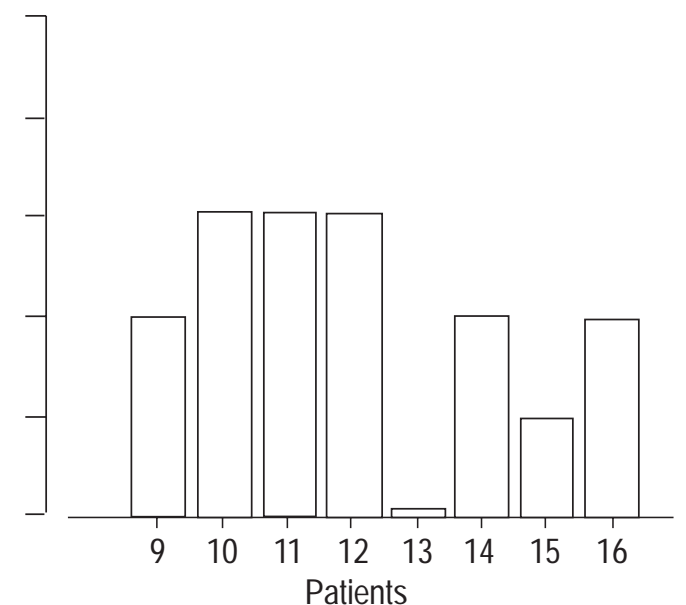

Fig. 1 - a, b) Two representative examples of a quantitative reverse transcriptase polymerase chain reaction (RT-PCR) for the detection of transforming growth factor (TGF)- $\beta_{1}$ in a patient with acute exacerbation (a; patient 1 ) and a patient with chronic stable disease (b; patient 12). Lane one represents the molecular weight standard, lanes 2-7 represent the amplification results for a combined amplification of GAPDH, the decreasing amount of the serially diluted TGF- $\beta$ competitor (TGF- $\beta$ Comp.) ranging $10-10^{-4}$ amol, and the specific gene of the patients (TGF- $\beta_{1}$ Pat.). In patient 1 (acute), no signal was detectable, in patient 12 (chronic stable), equal amplifcation products were seen at $10^{-1}$ amol (arrow, lane 4). c, d) Individual results of the quantitative RT-PCR for TGF- $\beta_{1}\left(\right.$ amol- $\mu \mathrm{L}^{-1}$ ribonucleic acid (RNA)) in all patients. Only two patients with acute disease (c; patients 6 and 8 ) weakly expressed TGF$\beta_{1}$. TGF- $\beta_{1}$ was seen in all patients with chronic stable disease (d).

respiratory epithelia were highly metaplastic in half of the patients, whereas in chronic stable disease, the epithelium appeared unchanged (fig. 3b).

\section{Immunohistochemistry}

The difference of immunoreactivity was most obvious for TGF $\beta_{1}$. In chronic stable disease (fig. 4b), an intense staining was seen, mainly in small mononuclear cells (typically lymphocytes) that were scattered throughout the subepithelial layer as well as in some of the endothelial cells of the detectable vessels. In most patients

Table 2. - Number of immunocompetent cells in cystic fibrosis (CF) biopsies of 16 CF patients

\begin{tabular}{lcccc}
\hline Stain/immunostain & Cell & $\begin{array}{c}\text { Acute } \\
(\mathrm{n}=8)\end{array}$ & $\begin{array}{c}\text { Chronic } \\
\text { stable } \\
(\mathrm{n}=8)\end{array}$ & $\mathrm{p}$-value* \\
\hline Haematoxylin-eosin & PMN & $49.8 \pm 21.0$ & $7.5 \pm 4.3$ & $\mathrm{p}<0.001$ \\
& Ly/PI & $4.3 \pm 2.5$ & $23.0 \pm 6.7$ & $\mathrm{p}<0.001$ \\
TGF- $\beta_{1}$ & & & & \\
immunoreactive & PMN & $1.1 \pm 1.7$ & $0.6 \pm 0.7$ & $\mathrm{NS}$ \\
& Ly/PI & $2.4 \pm 1.1$ & $12.5 \pm 6.7$ & $\mathrm{p}<0.01$ \\
IL-8 immunoreactive & PMN & $10.1 \pm 6.4$ & $6.3 \pm 4.1$ & $\mathrm{NS}$ \\
& Ly/PI & $0.8 \pm 0.7$ & $0.6 \pm 0.9$ & $\mathrm{NS}$ \\
\hline
\end{tabular}

Data are presented as number of cells per microscopic field \pm SD. TGF: transforming growth factor; IL: interleukin; PMN: polymorphonuclear cells; Ly/PI: lymphocytes or plasma cells. *: Wilcoxon rank from test. with acute exacerbation, no immunoreactivity for TGF- $\beta_{1}$ was observed (fig. 4a), although a few mononuclear cells could be found in the subepithelium that stained weakly for TGF- $\beta_{1}$. The number of lymphocytes and plasma cells immunoreactive for TGF- $\beta_{1}$ was significantly lower in patients with an acute exacerbation compared to chronic stable disease $(2.4 \pm 1.1$ versus $125 \pm 6.7 ; \mathrm{p}=0.002$; see table 2).

All patients were immunoreactive for IL-8. The number of PMNs and lymphocytes that stained for IL- 8 did not differ between both groups (table 2). In acute patients, weak epithelial staining for IL-8 was observed. Most cases revealed a strong endothelial reaction in the small blood vessels of the subepithelial layer (fig. 4c) as well as positive cells throughout the tissue, mostly PMNs. In chronic stable patients, the signal for IL- 8 was confined to mononuclear cells, whereas both epithelium and endothelium did not react with the antibody (fig. 4d).

IFN- $\gamma$ antibodies stained cells and extracellular compartments both in the epithelium and subepithelial compartments (data not shown). The majority of IFN- $\gamma$-expressing cells were lymphocytes. Most of the staining reaction was seen in chronic stable patients in the subepithelial compartment, mainly extracellularely. In acute exacerbations, only a weak signal, related to lymphocytes, was detected.

In order to investigate the reproducibility of the data, each experiment (RT-PCR and immunostaining) was performed in duplicate at least from two to three biopsies taken from different sites of the bronchial tree. Within the 


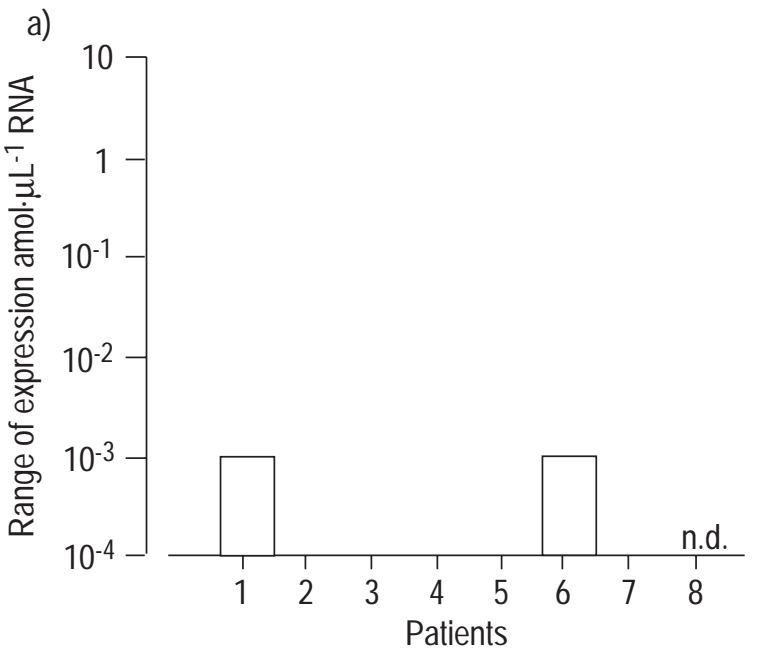

b)

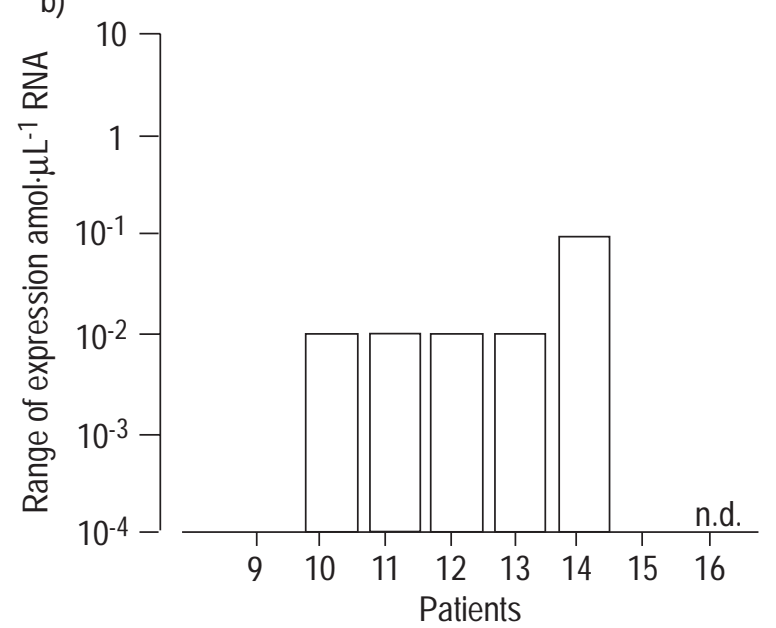

Fig. 2 - Individual results of the quantitative reverse transcriptase polymerase chain reaction for interferon (IFN)- $\gamma\left(\mathrm{amol} \cdot \mu \mathrm{L}^{-1}\right.$ ribonucleic acid (RNA)) in patients with acute $(\mathrm{a} ; \mathrm{n}=7)$ and chronic stable disease $(\mathrm{b}$; $n=7$ ). In patient $8 / 16$, the reaction for IFN- $\gamma$ could not be performed due to the small amount of RNA obtained, therefore this patient has not been included in the total patient number (the patient appears twice because they had both an acute exacerbation and a chronic stable condition). Only two patients with acute disease (1 and 6) expressed IFN- $\gamma$.

chosen decadic logarithmic steps of assessment of gene transcription (representing a factor of 10 within each dilution step), no intraindividual difference in transcription range was observed in different specimens of each patient. Moreover, histological and immunohistochemical assessment performed at different sites of the biopsy gave consistently reproducible results within each patient. The number of cells staining for IL-8 or TGF- $\beta_{1}$ within one field of $16,300 \mu^{2}$ did not vary by more than 2 -fold within one patient (see table 2).

\section{Discussion}

Immunohistochemical and molecular assessment of cytokine expression in bronchial biopsies from CF patients with acute pulmonary exacerbation and chronic stable disease revealed striking differences regarding the expression of TGF- $\beta_{1}$ and IFN- $\gamma$. In addition, histological and immunohistochemical results demonstrated a compart- mentalized immune response between the epithelium and the subepithelial layer. In chronic stable disease, the inflammatory response was characterized by lymphoplasmacellular infiltrates and a strong expression of TGF- $\beta_{1}$ and IFN- $\gamma$ in the subepithelial layer, whereas in patients with acute exacerbation, dense neutrophil infiltrates and a lack of TGF- $\beta_{1}$ and IFN- $\gamma$ were found.

It has been argued that the severity of pulmonary disease in CF patients might be a result of different CF gene mutations [5]. Nonetheless, clinical assessment reveals considerable variation in the extent of pulmonary involvement, even among patients representing identical CFTR-genotypes $[5,19,20]$. Although substantial clinical information is available regarding the impact of bacteria, fungi and viruses on mucosal inflammation in $\mathrm{CF}$ patients $[4$, $21,22]$, this does not necessarily reflect on the patient's individual course of disease. The range of variation within the genotypic groups and the variable impact of infectious agents [19] suggests the existence of additional mechanisms related to the patient's immune response. In the current study, the distribution of CF patients homozygotic for dF508 was equal between both clinical groups, four of them presenting with chronic stable disease and the others with acute exacerbation. Despite this identical genotype, a considerable clinical differences were observed, such as wide range of FEV1 values and differences in the need of antibiotic treatment. Thus, progression of pulmonary disease cannot be entirely explained by the genetic background. With regard to the immune response, there was a marked difference between both clinical groups, especially for expression of TGF- $\beta_{1}$ and IFN-g combined with a characteristic cellular infiltrate in each group. Thus, it could be argued that an imbalanced immune response may contribute to the progression of pulmonary disease in $\mathrm{CF}$.

The cellular immune response in $\mathrm{CF}$ patients is thought to be mainly characterized by an accumulation of neutrophil granulocytes $[3,4]$ as a result of the production and release of IL-8 [6-8, 10, 11, 23]. Consistent with this view, the current patients with acute exacerbation showed dense infiltrates of polymorphonuclear granulocytes and a positive staining for IL-8 in the subepithelial blood vessels. However, the patients with chronic stable disease lacked this positive staining for IL-8 in their subepithelial vessels, and demonstrated a predominantly lymphoplasmacellular infiltrate, as assessed by double staining. These cells were immunoreactive for TGF- $\beta_{1}$. Notably, both changes in cellularity and gene expression occurred in the subepithelial compartment. This could reflect the differences between the current data and previous studies which used the cellular material obtained by BAL or epithelial brushings from smaller airways.

TGF- $\beta_{1}$ has been demonstrated to downregulate the IL8 -dependent migration of neutrophils through endothelial monolayers [24]. It is therefore noteworthy that the stable patients is the present study with very mild disease had the highest expression of TGF- $\beta_{1}$ and a mucosal inflammation without polymorphonuclear infiltrates. Thus, considering the destructive capacity of neutrophil elastase and oxidative radicals released from activated neutrophils, an overexpression of TGF- $\beta_{1}$ during chronic mucosal inflammation may be one of the important mechanisms to prevent epithelial damage in CF airway inflammation. Notably, this reduced neutrophil inflammation took place 

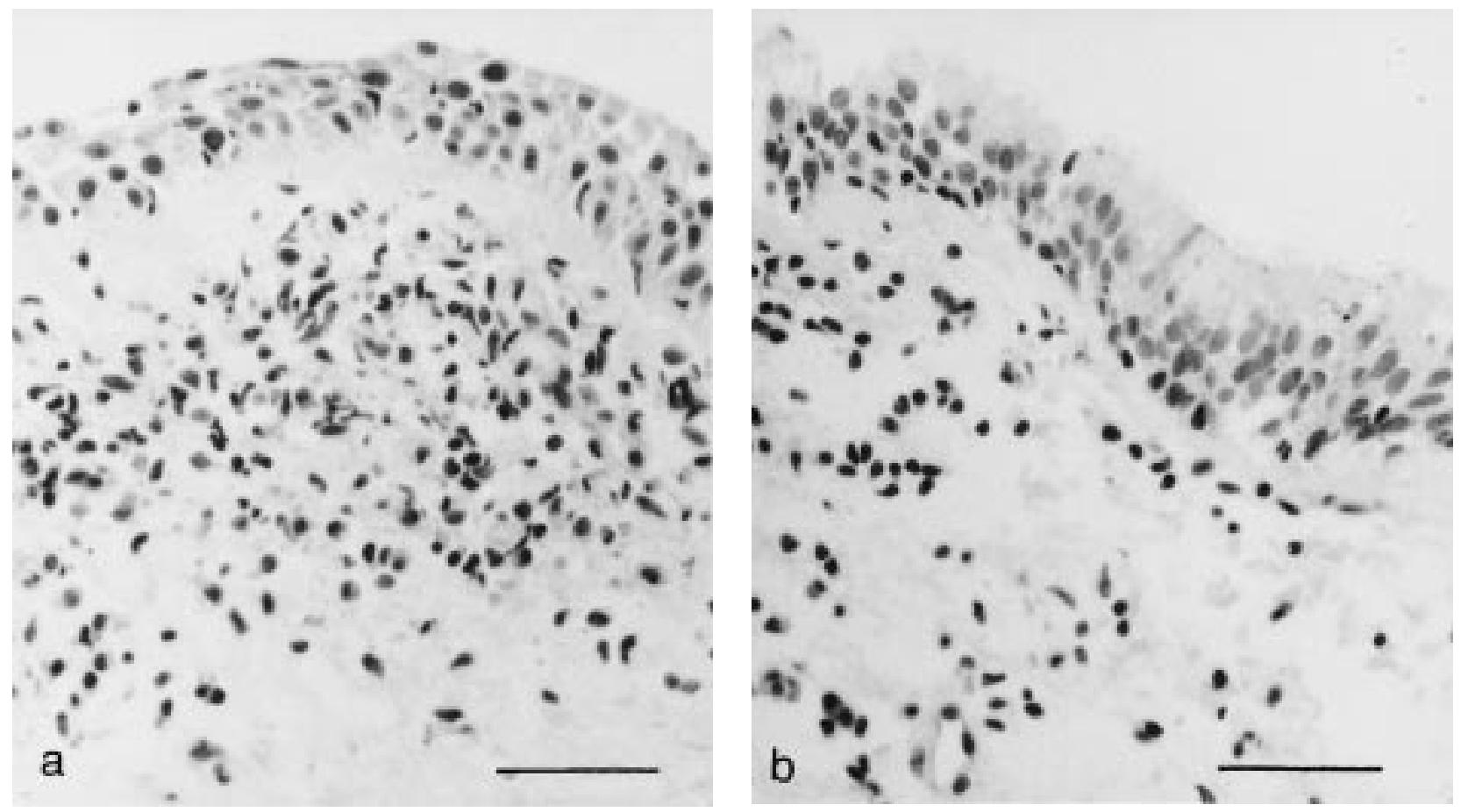

Fig. 3 - Haematoxylin-eosin staining for a representative patient with acute disease (a) and chronic stable disease (b). Slides were examined and photographed on a Nikon Microphot FXA microscope (Magnification approx. $1 \times 400$ ). In acute disease, a metaplastic epithelium with a thickened basal membrane was found. Dense cellular infiltrates consisting mostly of neutrophil and eosinophil granulocytes are seen in the subepithelial tissue. In the chronic stable disease, the respiratory epithelium appears unchanged. Mononuclear cells are scattered throughout the subepithelium (mostly lymphocytes). Internal scale bars $=25 \mu \mathrm{m}$.

despite a comparable and persisting bacterial colonisation of the epithelia in both groups (table 1).

It cannot be entirely ruled out that microabscesses in the biopsies could have influenced the RT-PCR results. However, histological assessment, even in those biopsies, where up to five sections from different sides of the biopsy were investigated, did not show inhomogeneous inflammatory processes. Thus, it is rather unlikely that the differences in gene expression should be attributed to microabscesses.

Due to the fact that those current observations could reflect a momentary condition within a dynamic process, it is still not clear whether a continuous induction of TGF- $\beta_{1}$ is representative for the immune response of patients with chronic stable disease. However, there was the opportunity to study one patient with very mild disease (patient 8/16) during their first acute exacerbation and 4 months later. Molecular assessment of the immune reaction after complete clinical recovery revealed an increase of the expression of TGF- $\beta_{1}$ comparable to those found in the other chronic stable patients who had no exacerbation in the preceding 12 months. In addition to a hypothetical stabilization of an immune response by TGF- $\beta_{1}$ expression in a chronic inflammatory setting, it is also conceivable that an altered cytokine profile could be the consequence of infectious pathogens. Further longitudinal observations are required to distinguish whether the differences in cytokine expression are a cause or consequence of acute exacerbations.

Nevertheless, it is quite unlikely that only one mediator should be responsible for the orchestration of the immune network in CF airway inflammation. Rather, it is con- ceivable that the balance between different mediators during each step decides the development and progression of airway inflammation. Regarding the expression of IL-4 and IL-10, no correlation with the clinical course was found. In contrast, expression of IFN- $\gamma$ as a stimulant for a specific, antigen-directed cellular immune reaction $[25,26]$ showed considerable differences between both groups. The functional relevance of this observation is not yet clear, although this could mean that the immune response during acute exacerbation is intensified due to a lack of specificity and effectivity.

In this pilot project, the regulation of a probably dysbalanced immune response has not been further investigated, due to the limited number of patients and the size of the biopsies. Nonetheless, these results demonstrate a remarkable correlation between the specific cytokine patterns measured in bronchial biopsies and the clinical course of CF.

In conclusion, this work showed a remarkable correlation between cytokine pattern and the clinical course of CF. High expression of TGF- $\beta_{1}$ and IFN-8 was associated with mild disease, whereas no or very weak expression of these cytokines was typical for patients with acute disease and frequent exacerbations suggesting a contribution of the immune response to the progression of pulmonary disease in $\mathrm{CF}$.

Further studies combining clinical and microbiological assessment of pulmonary disease and detailed investigation of the molecular pattern of inflammation are needed to elucidate the possible role of transforming growth factor- $\beta_{1}$ and interferon gamma within the cytokine network in attenuating persistently upregulated immune response during airway inflammation in cystic fibrosis. 

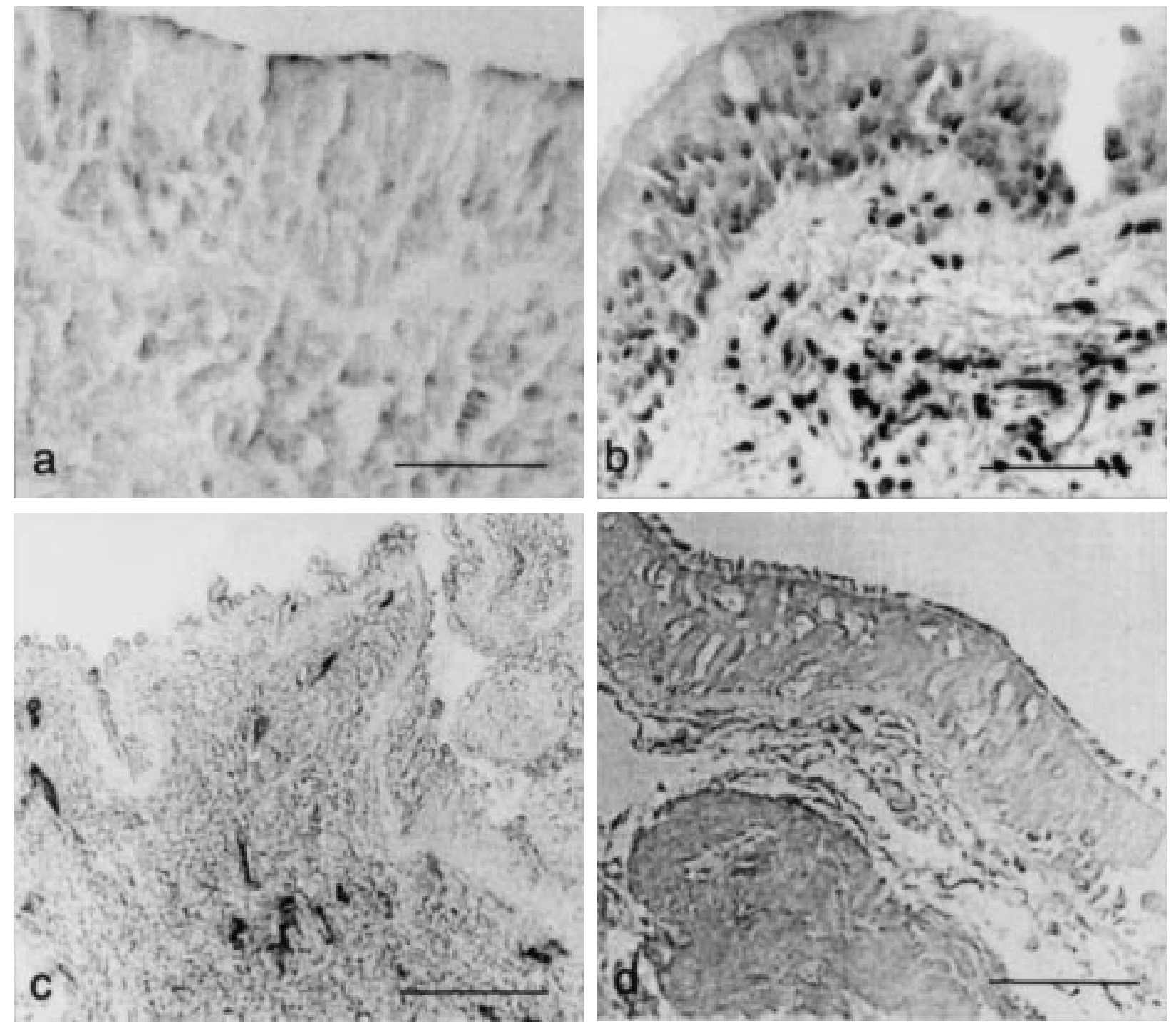

Fig. 4 - a, c) Representative mucosal biopsies from patients from patients with acute disease; b, d) specimens from patients with chronic stable disease. Slides were examined and photographed on a Nikon Microphot FXA microscope (Magnification approx. 1×400). Immunohistochemical staining was performed for transforming growth factor (TGF)- $\beta_{1}(a, b)$ and interleukin (IL)-8 (c, d). In the case with acute disease no positive signal for TGF- $\beta_{1}$ could be observed (a), whereas in the patient with chronic stable disease mononuclear cells in the subepithelium stained for TGF- $\beta_{1}$ (b). In (c), subepithelial vessels in acute exacerbation stained for IL-8. In chronic stable disease, vessels did not stain for IL-8 (d). Internal scale bars $=25 \mu \mathrm{m}$.

\section{References}

1. Rommens JM, Iannuzzi MC, Kerem BS, et al. Identification of the cystic fibrosis gene: chromosome walking and jumping. Science 1989; 245: 1059-1065.

2. Davies PB, Drumm M, Konstan MW. State of the art: Cystic fibrosis. Am J Respir Crit Care Med 1996; 154: pp. $1229-1256$.

3. Danel C, Erzurum SP, McElvaney NG, Crystal RG. Quantitative assessment of the epithelial and inflammatory cell populations in large airways of normal and individuals with cystic fibrosis. Am J Respir Crit Care Med 1996; 153: 362-366.

4. Berger M. Inflammation in the lung in cystic fibrosis. Clin Rev in Allergy 1991; 9: 119-143.

5. Kerem E, Kerem B. Genotype-Phenotype Correlations in cystic fibrosis. Pediatr Pulmonol 1996; 22: 387-395.

6. Bonfield TL, Panuska JR, Konstan MW, et al. Inflammatory cytokines in cystic fibrosis lungs. $\mathrm{Am} \mathrm{J}$ Respir Crit Care Med 1995; 152: 2111-2118.
7. Noah TL, Black HR, Cheng PW, Wood RE, Leigh MW. Nasal and bronchoalveolar lavage fluid cytokines in early cystic fibrosis. J Infect Dis 1997; 175: 638-647.

8. Dean TP, Dai Y, Shute JK, Church MK, Warner JO. Interleukin-8 concentrations are elevated in bronchoalveolar lavage, sputum, and sera of children with cystic fibrosis. Pediatr Res 1993; 34: 159-161.

9. Bonfield TL, Konstan MW, Burfeind P, Panuska JR, Hilliard JB, Berger M. Normal bronchial epithelial cells constitutively produce the anti-inflammatory cytokine interleukin-10, which is downregulated in cystic fibrosis. Am J Respir Cell Mol Biol 1995; 13: 257-261.

10. Richman-Eisenstat J. Cytokine soup. Making sense of inflammation in cystic fibrosis. Pediatr Pulmonol 1996; 21: 3-5.

11. Salva PS, Doyle NA, Graham L, Eigen H, Doerschuk CM. TNF- $\alpha$, IL-8, soluble ICAM-1, and neutrophils in sputum of cystic fibrosis patients. Pediatr Pulmonol 1996; 21: 1119. 
12. Konstan MW, Hilliard KA, Norvell TM, Berger M. Bronchoalveolar lavage findings in cystic fibrosis patients with stable, clinically mild lung disease suggest ongoing infection and inflammation. Am J Respir Crit Care Med 1994; 150: 448-454.

13. Balough K, McCubbin M, Weinberger M, Smits W, Ahrens R, Fick R. The relationship between infection and inflammation in the early stages of lung disease from cystic fibrosis. Pediatr Pulmonol 1995; 20: 63-67.

14. Cantin A. Cystic fibrosis lung inflammation: early, sustained and severe. Am J Respir Crit Care Med 1995; 151: 939-941.

15. Khan TZ, Wagener JS, Bost T, Martinez J, Accurso FJ, Riches DWH. Early pulmonary inflammation in infants with cystic fibrosis. Am J Respir Crit Care Med 1995; 151: 1075-1082.

16. Koller DY, Götz M, Eichler I, Urbanek R. Eosinophilic activation in cystic fibrosis. Thorax 1994; 49: 496499.

17. American Thoracic Society. Standardization of spirometry-1987 update. Am Rev Respir Dis 1987; Attachment 2, 1285-1298.

18. Zapletal A, Samanek M, Paul T. Lung function in children and adolescents: methods, reference values. Progr Resp Res 1987; 22: 113-218.

19. The Cystic-Fibrosis Genotype-Phenotype Consortium. Correlation between genotype and phenotype in pati- ents with cystic fibrosis. N Engl J Med 1993; 329: 13081313.

20. Tsui-LC. The cystic fibrosis transmembrane conductance regulator gene. Am J Respir Crit Care Med 1995; 151: S47-50.

21. Kerem E, Corey M, Gold R, Levison H. Pulmonary function and clinical course in patients with cystic fibrosis after pulmonary colonization with Pseudomonas aeruginosa. J Pediatr 1990; 116: 714-719.

22. Milla CE, Wielinski CL, Regelmann WE. Clinical significance of the recovery of Aspergillus fumigatus species from the respiratory secretions of cystic fibrosis patients. Pediatr Pulmonol 1996; 21: 6-10.

23. Kelley J. State of the art: cytokines of the lung. Am Rev Respir Dis 1990; 141: 765-788.

24. Smith WB, Noack L, Khew-Goodall Y, Isenmann S, Vadas MA, Gamble JR. Transforming growth factor-beta 1 inhibits the production of IL-8 and the transmigration of neutrophils through activated endothelium. $J$ Immunol 1996; 157: 360-368.

25. Ijzermans JNM, Marquet RL. Interferon-gamma: a review. Immunobiol 1989; 179: 456-473.

26. Kunkel MA, Meraz JM, White KCF, et al. Targeted disruption of the Statl gene in mice reveals unexpected physiologic specificity in the JAK-STAT signaling pathway. Cell 1996; 84: 431-442. 